\title{
Dietary sea cucumber cerebroside alleviates orotic acid-induced excess hepatic adipopexis in rats
}

Bei Zhang ${ }^{1 \dagger}$, Changhu Xue ${ }^{1 \dagger}$, Xiaoqian $\mathrm{Hu}^{1}$, Jie Xu' ${ }^{1}$, Zhaojie $\mathrm{Li}^{1}$, Jingfeng Wang ${ }^{1}$, Teruyoshi Yanagita ${ }^{2}$, Yong Xue 1* $^{*}$ and Yuming Wang ${ }^{1 *}$

\begin{abstract}
Background: Nonalcoholic fatty liver disease (NAFLD) is a prevalent chronic liver disease in industrialized countries. The present study was undertaken to explore the preventive effect of dietary sea cucumber cerebroside (SCC) extracted from Acaudina molpadioides in fatty liver rats.

Methods: Male Wistar rats were randomly divided into four groups including normal control group, NAFLD model group, and two SCC-treated groups with SCC at $0.006 \%$ and $0.03 \%$ respectively. The fatty liver model was established by administration of $1 \%$ orotic acid $(O A)$ to the rats. After 10d, serum and hepatic lipid levels were detected. And the serum alanine aminotransferase (ALT) and aspartate aminotransferase (AST) activities were also determined. Besides, to gain the potential mechanism, the changes of key enzymes and gene expressions related to the hepatic lipid metabolism were measured.

Results: Dietary SCC at the level of $0.006 \%$ and $0.03 \%$ ameliorated the hepatic lipid accumulation in fatty liver rats. SCC administration elevated the serum triglyceride (TG) level and the ALT, AST activities in OA-fed rats. The activities of hepatic lipogenic enzymes including fatty acid synthase (FAS), malic enzyme (ME) and glucose-6-

phosphatedehydrogenase (G6PDH) were inhibited by SCC treatment. And the gene expressions of FAS, ME, G6PDH and sterol-regulatory element binding protein (SREBP-1C) were also reduced in rats fed SCC. However, dietary SCC didn't affect the activity and mRNA expression of carnitine palmitoyltransferase (CPT) in liver. Besides, suppression of microsomal triglyceride transfer protein (MTP) activity was observed in SCC-feeding rats.
\end{abstract}

Conclusions: These results suggested that dietary SCC could attenuate hepatic steatosis due to its inhibition of hepatic lipogenic gene expression and enzyme activity and the enhancement of TG secretion from liver.

Keywords: Sea cucumber cerebroside, Orotic acid, Fatty liver, Lipogenesis, Microsomal triglyceride transfer protein

\section{Background}

The metabolic syndrome, a cluster of metabolic abnormalities such as hyperlipidemia, diabetes mellitus, and hypertension, is a widespread disease in industrialized countries and contributes to the increase in cardiovascular morbidity and mortality [1-3]. Nonalcoholic fatty liver disease (NAFLD), an increasingly prevalent chronic liver disease in many countries, has been associated with

\footnotetext{
* Correspondence: xueyong@ouc.edu.cn; wangyuming@ouc.edu.cn ${ }^{\dagger}$ Equal contributors

${ }^{1}$ College of Food Science and Engineering, Ocean University of China, Qingdao, China

Full list of author information is available at the end of the article
}

insulin resistance and metabolic syndrome. NAFLD is the preferred term to describe the spectrum of liver damage ranging from hepatic steatosis to steatohepatitis, liver fibrosis, and cirrhosis [4]. It has been reported that occurrence of NAFLD ranges from $10 \%$ to $24 \%$ in different populations, and even reaches $74 \%$ in obese individuals [5]. This prevalence prompted studies to focus on the prevention or therapy of NAFLD. Though the processes through which steatohepatitis evolves from hepatic steatosis are not fully understood, it is necessary to develop effective therapies for the treatment of NAFLD and to discover nutrients that will reduce the risk of NAFLD.

\section{Biomed Central}

(c) 2012 Zhang et al.; licensee BioMed Central Ltd. This is an Open Access article distributed under the terms of the Creative Commons Attribution License (http://creativecommons.org/licenses/by/2.0), which permits unrestricted use, distribution, and reproduction in any medium, provided the original work is properly cited. 
Orotic acid $(\mathrm{OA})$, an intermediate in pyrimidine biosynthesis, is known to evoke fatty liver when fed over an appreciable amount in rats [6,7]. The model established by OA-supplemented diet to rats reflects the natural etiologic setting in which NAFLD develops[8]. OAinduced NAFLD has been reported to be possibly generated, in part, by reduction of very low density lipoprotein (VLDL) secretion [9], enhancement of triglyceride (TG) synthesis $[7,10]$ and decrease in fatty acid $\beta$ - oxidation $[8,11,12]$. The hepatic TG accumulation caused by OA which has been demonstrated before was likely to be alleviated by dietary nutrients. Buang Y has found that dietay phosphatidylcholine alleviated OA-induced hepatic steatosis and hepatomegaly through downregulation of fatty acid synthesis and up-regulation of $\beta$-oxidation in rats [13]. Dietary saponins of sea cucumber attenuating fatty liver partly associated with the promoted lipolysis via PPAR $\alpha$ activation and inhibited SREBP-1cmediated lipogenisis [12]. But no study was undertaken to ascertain the influence of dietary glycolipids against NAFLD.

The existence of glycolipids has been determined in wide range. Early in 2000, Suzuki H has detected glycolipids from several plants [14]. Recent growing interest in the physiological functions of glycolipid as a nutrient in food has generated. The antifungal and antibacterial activities in the three sphingolipids isolated from cucumber Cucumis sativus $L$. has been evaluated recently [15]. Glycolipids has been shown great anticancer potency through inducing Th1-biased cytokines and CD8/CD4 T cells in mice bearing breast and lung cancers [16]. Nakagawa $\mathrm{R}$ discovered that galactosylceramide activated NKT cells and then produced IFN- $\gamma$, which both increased the innate antitumor cytotoxicity of NK cells and expessed inhibition of tumor metastasis to liver through the adaptive antitumor response of CD8+ T cells in mice [17]. The effect of glycolipids on the immunomodulatory has also been investigated peviously[18]. The cerebroside, a type of endogenous glycolipid extensively existing in cell membranes of fungi, plants, animals and marine organism [19], has been proven to exert pharmacological effects, such as antibacterial, antihepatotoxic, anti-tumor and neuroprotective activities [20-23]. And the cerebroside was also reported to regulate lipid levels according to Cohn Jeffrey [24]. The marine cerebroside displayed strong bioactivity as a result of the special ocean circulation, although there are fewer classes and lower contents of cerebrosides in marine than living in the ground. Sea cucumber of Echinodermata is an important marine food and medical material in Asian countries. Researches on the influence of dietary whole sea cucumber on lipid metabolism have been much investigated. Tanaka $\mathrm{K}$ has found that dietary 5\% black sea cucumber (Stichophus japonicus) revealed hypolipidemic effect in rats [25]. The results of Wang's study on sea cucumber (Pearsonothuria graeffei and Apostichopus japonicus) displayed its lipid-lowering effect in hypercholesteremic rats [26]. However, it is unknown whether the sea cucumber cerebroside (SCC) may prevent against lipid metabolism disorder in animal models.

Whereas the SCC may be expected to exhibit various physiological functions based on the results obtained from cerebrosides from other sources. Nonetheless, reports on biological evaluation of lipid metabolism on SCC are unavailable. Therefore, the present work was carried out to discuss the effect of SCC on the lipids of serum and liver in rats fed OA diet. To gain an insight into the mechanism of SCC on the NAFLD caused by $\mathrm{OA}$, response of enzymatic activities and mRNA expression involved in hepatic lipid metabolism was also measured.

\section{Methods}

\section{Isolation and purification of cerebroside}

The dried body wall of sea cucumber Acaudina molpadioides was grinded to powder and extracted three times with $\mathrm{EtOH} / \mathrm{H}_{2} \mathrm{O}$ (4:1). The combined extracts were concentrated in vacuo to give an aqueous solution. The aqueous solution was extracted with three portions of $\mathrm{n}$ hexane. The organic layer was concentrated in vacuo and the residue was washed with cold acetone to give an acetone-insoluble fraction. The acetone-insoluble part was chromatographed on Silica gel column(solvent $\mathrm{CHCl}_{3} / \mathrm{MeOH}$ 99:1 to $\mathrm{CHCl}_{3} / \mathrm{MeOH} / \mathrm{H}_{2} \mathrm{O}$ 80:15:1) to afford cerebrosides (purity $\geq 95 \%$ ) [27]. The structure of the SCC is shown in Figure 1.

\section{Animals and diets}

All aspects of the experiment were conducted according to guidelines provided by the ethical committee of experimental animal care at Ocean University of China (OUC, China).

Male Sprague-Dawley rats aged 5wk were purchased from Vital River (Beijing, China) and housed individually in an air-conditioned room with a 12-h light/dark cycle, a constant temperature of $24^{\circ} \mathrm{C}$ and relative humidity of $65 \pm 15 \%$. After a 1 -wk adaptation period, rats were randomly divided into four groups $(n=6)$. The animals were then assigned to the following four different diets: 1) AIN-93 G diet (Cont); 2) AIN-93 G diet with 1\% OA contained (OA); 3) 1\% OA-contained AIN-93 G diet plus $0.006 \% \mathrm{SCC}(\mathrm{OA}+0.006 \%) ; 4) 1 \%$ OA-contained AIN-93 G diet plus $0.03 \%$ SCC $(\mathrm{OA}+0.03 \%)$. Basal experimental diets were prepared according to the recommendations of the American Institute of Nutrition (AIN). The composition of the diets and SCC concentration were shown in Table 1. Rats were allowed free 


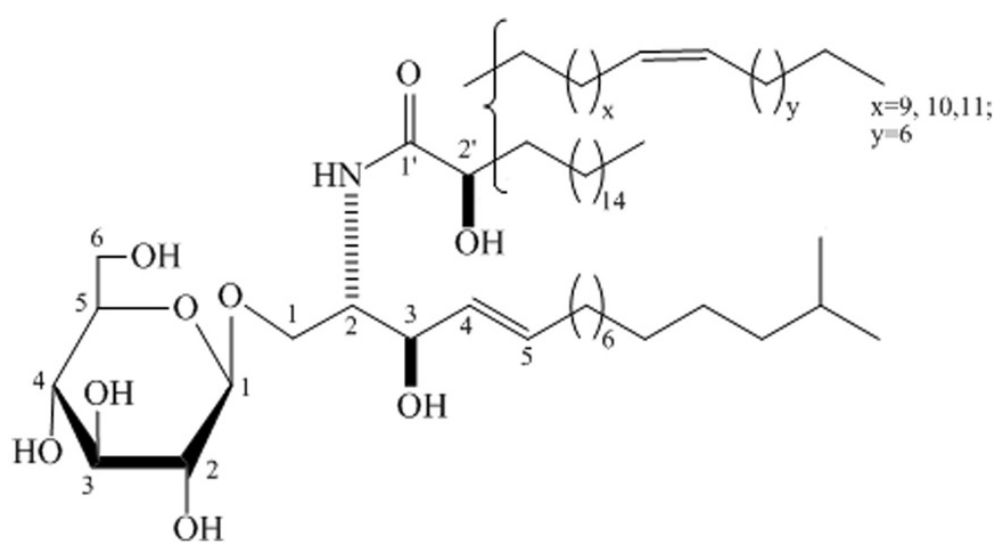

Figure 1 The structure of SCC from Acaudina molpadioides.

access to water and food for 10 days. At the end of the feeding period, all rats were killed by bleeding from the abdominal aorta under diethyl ether anesthesia after overnight fasting. Serum was separated from the whole blood by centrifugation at $1500^{*} \mathrm{~g}$ for $10 \mathrm{~min}$ at $4^{\circ} \mathrm{C}$. Liver, perirenal adipose and epididymal adipose were immediately excised for analysis.

\section{Serum biochemistry analysis}

Serum total cholesterol (TC), TG and low density lipoprotein cholesterol (LDL-c) were measured using enzymatic reagent kits from Biosino (Beijing, China) according to the manufacturer's instructions. Serum ALT and AST activities were determined using enzymatic kits from Njjctech (Nanjing, China).

\section{Measurement of hepatic lipid levels}

Hepatic lipids were extracted and purified according to the method of Folch [28] and then dissolved with 10\% Triton X-100. The concentrations of TG and TC in

Table 1 Composition of experimental diets ( $\mathrm{g} / \mathrm{kg}$ diet)

\begin{tabular}{lrrll}
\hline Ingredients & Cont & OA & OA $+\mathbf{0 . 0 0 6}$ & OA + 0.03 \% \\
\hline Casein & 200 & 200 & 200 & 200 \\
Cornstarch & 500 & 490 & 489.94 & 489.7 \\
Sucrose & 100 & 100 & 100 & 100 \\
Corn oil & 100 & 100 & 100 & 100 \\
Mineral mix (AIN-93 G) & 35 & 35 & 35 & 35 \\
Vitamin mix(AIN-93 G) & 10 & 10 & 10 & 10 \\
Choline bitartrate & 2 & 2 & 2 & 2 \\
Cellulose & 50 & 50 & 50 & 50 \\
L-cystine & 3 & 3 & 3 & 3 \\
OA & - & 10 & 10 & 10 \\
SCC & - & - & 0.06 & 0.3 \\
\hline
\end{tabular}

Vitamin mixture (AIN-93VX; DyetsInc.). Mineral mixture (AIN-93 G; DyetsInc.). liver were detected using enzymatic reagent kits from Biosino(Beijing, China), and the hepatic phospholipid (PL) levels were determined according to the methods of Bartlett [29].

\section{Preparation of liver subcellular fractions and assays of hepatic enzyme activities}

Portions of the fresh livers from individual rats were homogenized in ice-cold $0.25 \mathrm{M}$ sucrose solution containing $10 \mathrm{mM}$ Tris- $\mathrm{HCl}$ buffer (pH7.4) and $1 \mathrm{mM}$ EDTA. After precipitating the nuclei fraction, the supernatant was centrifuged at $10,000^{*} \mathrm{~g}$ for $10 \mathrm{~min}$ at $4^{\circ} \mathrm{C}$ to obtain mitochondria, which was used for carnitinepalmitoyl transferase (CPT) activity as described previously [30]. The resulting supernatant was re-centrifuged at $125,000 * \mathrm{~g}$ for $60 \mathrm{~min}$,the supernatant (cytosol) was used for the assays of fatty acid synthase (FAS), malic enzyme (ME) and glucose-6-phosphatedehydrogenase (G6PDH) activities as described [30-32], and the precipitate(microsomes) was used for the assays of microsomal triglyceride transfer protein (MTP) activity with an MTP assay kit from Roar Biomedical (New York, US). The protein concentration was determined according to the method of Lowry [33], with bovine serum albumin used as the standard.

\section{Determination of mRNA expression of hepatic genes}

For analysis of gene expression, total cellular RNA was extracted from $100 \mathrm{mg}$ frozen liver samples using the Trizol reagent (Invitrogen, USA) according to the manufacturer's recommended procedures. RNA concentrations were determined spectrophotometrically and $1 \mu \mathrm{g}$ total RNA was reverse transcribed using an MMLV reverse transcriptase kit (Promega, USA) and random primers (TOYOBO, Japan) in a reaction volume of $50 \mathrm{uL}$ for cDNA synthesis. The concentration of cDNA was analyzed by real-time detection PCR (ABI Prism 7500 Sequence Detection System, USA) using Sybr Green I 
Master Mix (TOYOBO, Japan). PCR was carried out with a final volume of $30 \mu \mathrm{L}$ reaction mixture containing:15 $\mu \mathrm{L}$ master mix, $2 \mu \mathrm{L}$ first-strand cDNA, $1 \mu \mathrm{L}$ primer with each forward and reverse, and $\mathrm{H}_{2} \mathrm{O}$ to make up $30 \mu \mathrm{L}$. A dilution curve from one cDNA source using dilutions of 1:2, 1:4, 1:8 and a no-template control was run for each gene including sterol- regulatory element binding protein (SREBP-1c). The gene expression was determined by relative quantification using the standard curve method. A final melting curve guaranteed the authenticity of the target product. The expression signal of the house keeping gene $B$-actin served as an internal control for normalization. The primer sequences used for real-time PCR were shown in Table 2.

\section{Statistical analyses}

All the values are expressed as mean \pm standard error of the mean of six rats. All statistical analyses were performed using PC SAS software. One-way ANOVA and Tukey's post hoc test with least significant difference were used to compare group means. Homogeneity of variances was tested by Levene's test and Welch's ANOVA was used to compare group means when the group variances were unequal. $\mathrm{P}<0.05$ was considered statistically significant.

\section{Results}

Body weight gain, food intake, liver weight and adipose weight

As described in Table 3, the initial body weight (BW) was similar among the four groups. The amount of food consumed and food intake were almost the same in the period of experiment. OA feeding markedly elevated the liver weight compared to the controls $(\mathrm{P}<0.01)$, while the rats fed with SCC resulted in a significant decrease in liver weight as compared with the OA-feeding rats $(\mathrm{P}<0.05)$. There was no statistical difference among the four groups in the adipose tissue weight although dietary SCC slightly reduced the weight of perirenal adipose.

\section{Serum and hepatic parameters}

Table 4 summarized the lipid levels of the rats in serum and liver after 10 days of experiment. As compared with the controls, the serum TG and TC concentrations decreased $(\mathrm{P}<0.05, \mathrm{P}<0.05)$ in the rats fed with $\mathrm{OA}$, while the LDL-c level tended to decrease without significant difference. The rats in both SCC groups had higher serum TG content than the OA-fed rats $(\mathrm{P}<0.05, \mathrm{P}<0.05)$, but the TC and the LDL-c concentrations, although tended to reduce, were of no statistic difference in the two groups contrasting the OA group.

OA-feeding rats had a hepatic TG level four times higher than that in the controls $(\mathrm{P}<0.01)$. But SCC supplementation at $0.006 \%$ and $0.03 \%$ in rats both attenuated the OA-induced TG accumulation in contrast to the OA feeding $(\mathrm{P}<0.05, \mathrm{P}<0.01)$. The same tendency was observed in the hepatic TC level between the control and $\mathrm{OA}$ groups $(\mathrm{P}<0.05)$; dietary SCC at both doses reduced the TC concentration (P $<0.05, \mathrm{P}<0.01)$ in comparison with the OA diet. The PL content was of no marked difference among the four groups.

Besides, rats fed OA diet displayed severe NAFLDaccompanied liver injury. The activities of ALT increased about 2-fold in the OA group as compared with the controls $(\mathrm{P}<0.01)$ and the AST increased over 70\% $(\mathrm{P}<0.01)$. Administration of SCC at both doses ameliorated the hepatic damage. Dietary SCC at $0.006 \%$ reduced the ALT and AST activities by $45.3 \%$ and $25.6 \%$ respectively $(\mathrm{P}<0.05, \mathrm{P}<0.05)$ and $\mathrm{SCC}$ at $0.03 \%$ by $44.6 \%$ and $27.6 \%$ separately $\quad(\mathrm{P}<0.05$, $\mathrm{P}<0.05)$.

\section{Hepatic enzyme activities involved in lipogenesis metabolism}

OA administration increased the activities of FAS (89.8\%, $\mathrm{P}<0.01), \mathrm{ME}(24.6 \%, \mathrm{P}<0.05)$ and $\mathrm{G} 6 \mathrm{PDH}$ $(72.8 \%, \mathrm{P}<0.05)$ in liver, while feeding SCC to NAFLD rats significantly abolished the OA-induced increase. Dietary SCC at $0.006 \%$ reduced the activity of FAS by $36.5 \%(\mathrm{P}<0.01)$ and $\mathrm{G6PDH}$ by $26.0 \%(\mathrm{P}<0.01)$, and tended to decreased the activity of ME. Addition of SCC at $0.03 \%$ significantly reduced the activities of FAS, ME and G6PDH by 59.1\% $(\mathrm{P}<0.01), 42.8 \%(\mathrm{P}<0.01)$ and $30.9 \%(\mathrm{P}<0.01)$ (Figure 2).

Table 2 Primers used in this study

\begin{tabular}{llll}
\hline Gene & \multicolumn{1}{c}{ Forward/reverse primer } & Accession No. & Product length \\
\hline B-actin & GCAGATGTGGATCAGCAAGCGTCAAAGAAAGGGTGTAAAACG & NM_031144 & $111 \mathrm{bp}$ \\
FAS & GGAACTGAACGGCATTACTCGGCCCAAACCCCATTTTCTA & X62888 & $153 \mathrm{bp}$ \\
ME & TCACCTGCCCTAATGTCCCTCATGCCGTATCAACTTGTCC & NM_012600 & $185 \mathrm{bp}$ \\
G6PDH & GTTGGCAGCGGCAACTAAGGCATCACCCTGGTACAACTC & NM_031559 & $108 \mathrm{bp}$ \\
SREBP-1C & CGCTACCGTTCCTCTATCAATTCGCAGGGTCAGGTTCTC & AF286470 & $166 \mathrm{bp}$ \\
CPT1a & GCTTCCCCTTACTGGTTCCAACTGGCAGGCAATGAGACT & NM_012930 & $115 \mathrm{bp}$ \\
\hline
\end{tabular}

Gene-specific primers were designed by Primer Premier 5.0 software. 
Table 3 Effect of SCC on body weight gain, food intake, liver and adipose weights in rats

\begin{tabular}{lllll}
\hline & Cont & OA & OA +0.006 \% & OA + 0.03 \% \\
\hline Initial BW, g & $160 \pm 7$ & $160 \pm 6$ & $159 \pm 8$ & $158 \pm 7$ \\
Final BW, g & $248 \pm 9$ & $242 \pm 8$ & $238 \pm 5$ & $236 \pm 9$ \\
Food intake, g/d & $13.9 \pm 0.3$ & $13.8 \pm 0.3$ & $13.5 \pm 0.7$ & $13.2 \pm 1.6$ \\
Liver index, g/100 g BW & $3.77 \pm 0.3$ & $4.65 \pm 0.4^{* *}$ & $4.15 \pm 0.3^{\#}$ & $4.05 \pm 0.2^{\#}$ \\
Perirenal adipose, g/100 g BW & $0.85 \pm 0.11$ & $0.89 \pm 0.15$ & $0.84 \pm 0.17$ & $0.76 \pm 0.21$ \\
Epididymal adipose,g/100 g BW & $0.87 \pm 0.04$ & $0.90 \pm 0.06$ & $0.84 \pm 0.12$ & $0.87 \pm 0.23$ \\
\hline
\end{tabular}

Rats were fed the experimental diets for $10 \mathrm{~d}$.

Values are expressed as mean \pm standard error of the mean of six rats. ${ }^{* *} \mathrm{P}<0.01$, different from the control group; ${ }^{\#} \mathrm{P}<0.05$, different from the $\mathrm{OA}$ group.

\section{Relative mRNA expression of SREBP-1c and its target genes in liver}

In order to explore the molecular mechanism of the effect of SCC on the regulation of fatty acid lipogenesis, the expression of hepatic lipogenic genes was examined (Figure 3). Considering the integrated lipid-lowering effects of SCC, the group by dietary $0.03 \%$ SCC was chosen to access the changes of the mRNA expression for its most effective actions.

OA-supplemented diet to the rats up-regulated the mRNA expression of the lipogenic transcription factor SREBP-1c and its target genes (Figure 4). As compared with the controls, OA group exhibited a 1.4-fold SREBP1c mRNA expreesion $(\mathrm{P}<0.05), 1.3$-fold FAS $(\mathrm{P}<0.05)$ and 1.4-fold G6PDH $(\mathrm{P}<0.05)$; and the expression of ME mRNA tended to increase without significant difference. Dietary SCC at $0.03 \%$ prevented the OA-stimulated up-regulation of SREBP-1c and its response genes. SCC supplementation down-regulated the mRNA expression of FAS, G6PDH and ME by $17.2 \%(\mathrm{P}<0.05), 43.0 \%$ $(\mathrm{P}<0.05)$ and $24 \%(\mathrm{P}<0.05)$.

\section{Hepatic CPT activity and mRNA expression}

As depicted in Figure 4, 1\% OA addition reduced the activity of CPT, a key enzyme in fatty acid $\beta$-oxidation, by $37.1 \%(\mathrm{P}<0.05)$ as compared with the basal diet; The SCC at both doses tended to attenuate the reduction with no statistical difference. In line with the previous results, SCC at $0.03 \%$ was selected for considering the relative mRNA concentration of CPT1a. And consistent with the change of CPT activity, the CPT1a mRNA expression reduced $11 \%(\mathrm{P}<0.05)$ due to the supplemented$\mathrm{OA}$, but the SCC at $0.03 \%$ administration didn't affect its expression over the $\mathrm{OA}$ diet.

\section{Hepatic MTP activity}

To gain further insight into the relationship of ipid metabolism between the liver and the serum, the activity of MTP was detected (Figure 5). OA feeding markedly inhibited the MTP activity $(26.8 \%, \mathrm{P}<0.01)$, and SCC at $0.03 \%$ significantly attenuated the inhibition by $30.2 \%$ $(\mathrm{P}<0.05)$ in contrast to the OA diet.

Table 4 Effect of SCC on serum and hepatic parameters in rats

\begin{tabular}{|c|c|c|c|c|}
\hline & Cont & $O A$ & $O A+0.006 \%$ & $O A+0.03 \%$ \\
\hline \multicolumn{5}{|c|}{ Serum lipids, mmol/L } \\
\hline TG & $1.44 \pm 0.14$ & $0.69 \pm 0.12^{*}$ & $1.25 \pm 0.09^{\#}$ & $1.20 \pm 0.13^{\#}$ \\
\hline $\mathrm{TC}$ & $1.75 \pm 0.13$ & $1.47 \pm 0.16^{*}$ & $1.54 \pm 0.12$ & $1.52 \pm 0.10$ \\
\hline LDL-C & $1.53 \pm 0.11$ & $1.07 \pm 0.15$ & $1.19 \pm 0.12$ & $1.21 \pm 0.13$ \\
\hline \multicolumn{5}{|c|}{ Hepatic lipids, umol/g } \\
\hline TG & $15.8 \pm 1.3$ & $97.3 \pm 3.5^{* *}$ & $31.2 \pm 6.7^{\#}$ & $15.7 \pm 2.9^{\# \#}$ \\
\hline $\mathrm{TC}$ & $19.2 \pm 0.5$ & $26.7 \pm 3.2^{*}$ & $17.5 \pm 2.1^{\#}$ & $14.3 \pm 0.7^{\# \#}$ \\
\hline$P L$ & $34.5 \pm 1.2$ & $32.7 \pm 1.3$ & $33.2 \pm 1.3$ & $32.7 \pm 1.5$ \\
\hline \multicolumn{5}{|c|}{ Enzyme activities, IU/L } \\
\hline $\mathrm{ALT}$ & $9.21 \pm 2.01$ & $28.7 \pm 5.13^{* *}$ & $15.7 \pm 1.76^{\#}$ & $15.9 \pm 1.93^{\#}$ \\
\hline AST & $22.0 \pm 1.76$ & $39.5 \pm 3.65^{* *}$ & $29.4 \pm 1.01^{\#}$ & $28.1 \pm 1.65^{\#}$ \\
\hline
\end{tabular}

Rats were fed the experimental diets for $10 \mathrm{~d}$.

Values are expressed as mean \pm standard error of the mean of six rats.

${ }^{*} \mathrm{P}<0.05,{ }^{* *} \mathrm{P}<0.01$, different from the control group; ${ }^{\#} \mathrm{P}<0.05,{ }^{\# \#} \mathrm{P}<0.01$, different from the OA group. 

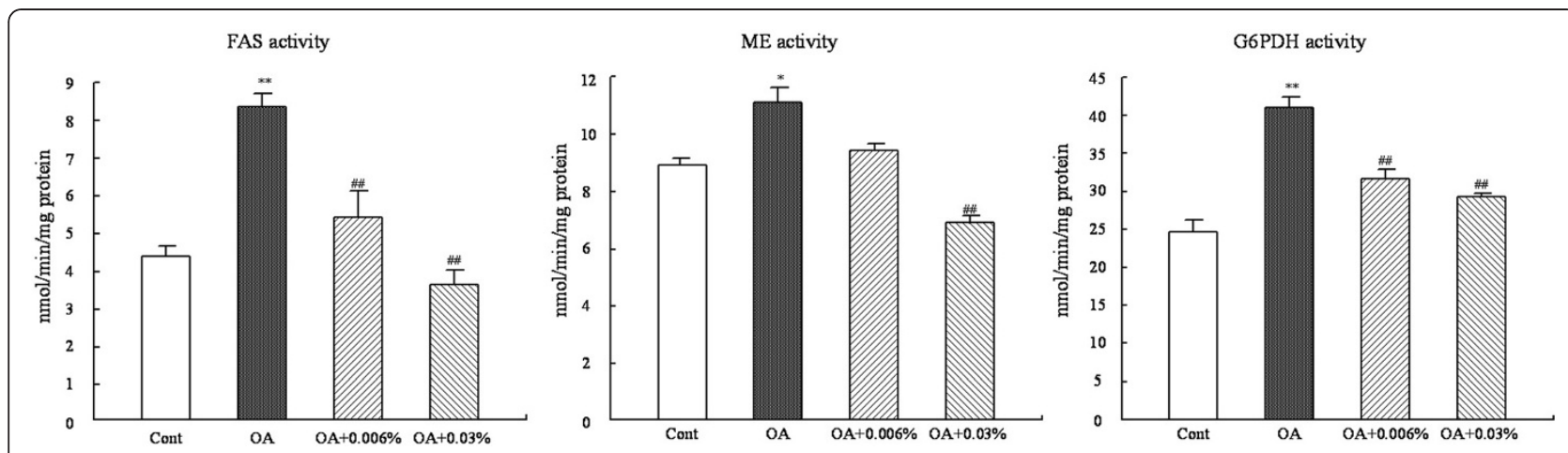

Figure 2 Effect of SCC on the activities of the enzymes related to fatty acid biosynthesis in rats. The activities of hepatic enzyme FAS, ME and G6PDH in rats fed Cont or OA-supplemented diet or the diet with OA+0.006\% SCC or OA $+0.03 \%$ SCC for 10d. Values are expressed as mean \pm standard error of the mean of six rats. ${ }^{*} \mathrm{P}<0.05,{ }^{* *} \mathrm{P}<0.01$, different from the control group; ${ }^{\# \#} \mathrm{P}<0.01$, different from the OA group.

\section{Discussion}

OA administration is widely used in studies of the mechanism of NAFLD. It is generally accepted that the enhancement of de novo lipid synthesis and access of hepatic fatty acids and inhibition of VLDL assembly and secretion result in OA-induced hepatic lipid accumulation [34]. The main objective of this study was to clarify if SCC contributed to NAFLD and to explore the

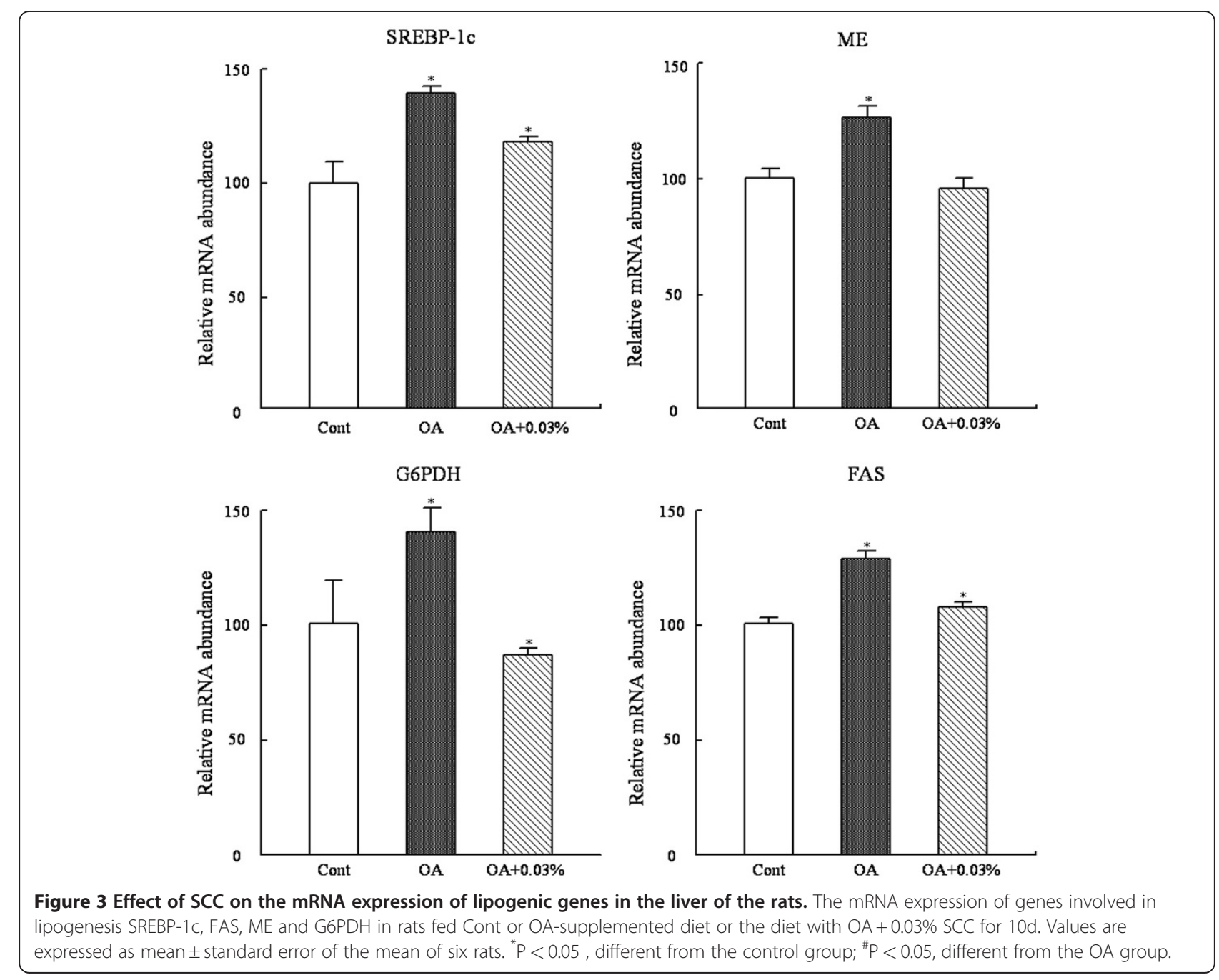



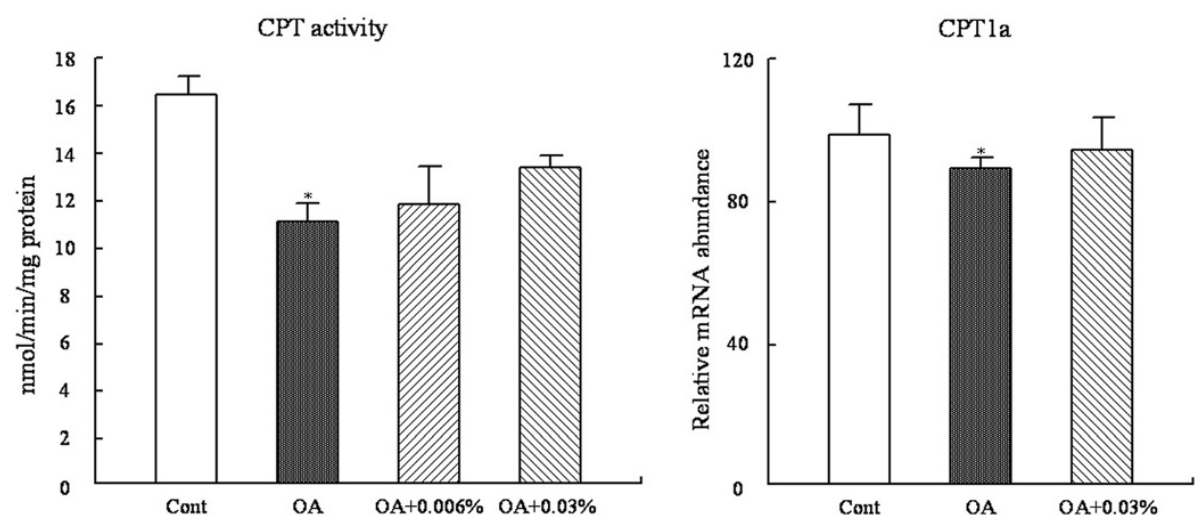

Figure 4 Effect of SCC on the CPT enzyme activity and mRNA expression in the liver of the rats. The activtiy of CPT in rats fed Cont or OA-supplemented diet or the diet with OA $+0.006 \%$ SCC or OA $+0.03 \%$ SCC and the mRNA expression of gene CPT1a in rats fed Cont or OA-supplemented diet or the diet withOA $+0.03 \%$ SCC for 10d. Values are expressed as mean \pm standard error of the mean of six rats. ${ }^{*} \mathrm{P}<0.05$, different from the control group.

potential mechanism in order to discover whether there is a new nutrient that prevents the development of NAFLD.

In the present study, dietary OA increased hepatic TG content by 4-fold, indicating the establishment of NAFLD model (Table 4). However, the raise in the hepatic TG concentration in rat was markedly reduced by simultaneous feeding of SCC at the dose of $0.006 \%$ and $0.03 \%$. The SCC at $0.03 \%$ decreased the lipid level to a much lower extent. The same tendency was observed in hepatic TC levels. The results above suggested that dietary SCC improved hepatic lipid accumulation in a doseresponse manner.

In addition, OA resulted in hepatic lipid accumulation and the increase in the activity of serum ALT and AST (Table 4). This indicated OA-induced NAFLD accompanied hepatic injury in rats. Nonetheless dietary SCC obviously attenuated the NAFLD-caused liver damage in rats via the declination of ALT and AST activities. Those results were in agreement with Zigmond E, who has found that $\beta$-glycosphingolipids alleviated liver damage through the immunomodulatory qualities inhibited local inflammation in the response organ in Cohen diabetic rats [35]. And to ourknowledg, this is the first report on the beneficial effect of SCC on NAFLD and concomitant liver injury in rats.

Several metabolic factors were involved in the hepatic lipid accumulation and the stimulation of hepatic fatty acid synthesis was the critical pathway of the NAFLD development. Therefore, the activities of the enzyme related to fatty acid biosynthesis were detected. And from Figure 1, a marked increase in the activity of FAS, a key enzyme involved in fatty acid synthesis, by OA diet was observed, and the activities of NADPH-generating enzymes required for FAS, ME and G6PDH, were also increasingly altered by OA-feeding, which was accordant with the study of $\mathrm{Hu}$ [12]. The present results demonstrated that SCC intake significantly suppressed the activities of those lipogenic enzymes, so one of the possible lipid-lowering mechanisms of SCC may be the inhibition of fatty acid biosynthesis.

As suggested in many researches, SREBP-1c acts a major part in the pathogenesis of NAFLD. The genes containing sterol-regulatory elements in their promoter regions in the lipogenic pathway are regulated by SREBP-1c including FAS, G6PDH and ME [36,37]. Over expression of SREBP-1c produces a pronounced hepatic TG accumulation leading to the development of NAFLD

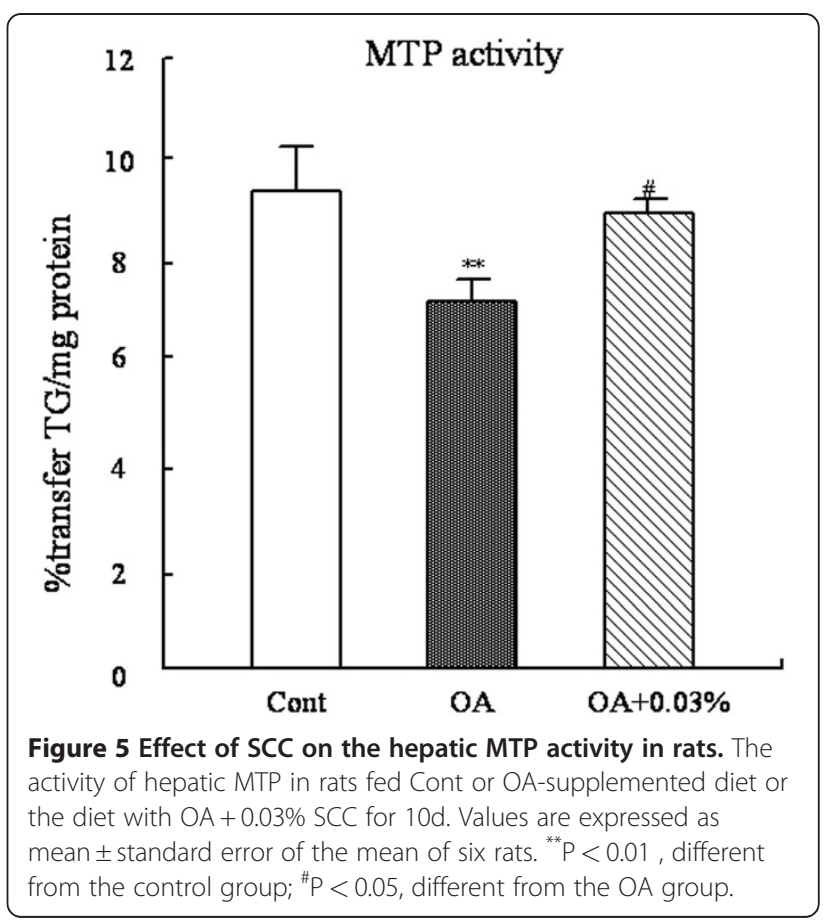


$[38,39]$. Thus, the depression of SREBP-1c expression in liver may potentially be responsible for the reduction of hepatic TG accumulation. As Figure 2 presented, SREBP-1c mRNA expression was strongly stimulated by OA diet, and supplementation of SCC inhibited its expression. And accordingly, the mRNA expressions of FAS, ME and G6PDH were concomitant markedly decreased in rats fed by simultaneously OA and SCC. Hence, the pathway of SCC-inhibition of lipogenis was supposed that SCC supplementation directly affected the SREBP-1c expression and then the alternation of these lipogenic gene transcriptions occur, thus reducing the activities of the responding enzymes. Another factor in charge of OA-induced hepatic TG accumulation is a declination of fatty acid $\beta$-oxidation[12,40]. Since the total $\beta$-oxidation critically depends on the mitochondrial oxidation, the activity of the rate-limiting enzyme of mitochondrial $\beta$-oxidation, CPT, was examined to reflect the $\beta$-oxidation ability (Figure 4). Consistent with Miyazawa S [41], dietary OA significantly decreased the hepatic $\beta$-oxidation capacity. However, SCC intake showed no significantly effect on the key enzyme activities, although a slight increase was observed by dietary SCC at both doses, especially at $0.03 \%$. The result of CPT1a mRNA expression was in accordance with the enzyme changes among the four groups. So the mechanism underlying the decrease in the activities of the lipolytic enzyme following SCC consumption was limited

Morifuji M has reported that the dietary OA decreased the level of serum TG [42]. In the present study, the dietary OA suppressed the serum TG and TC levels, but SCC intake significantly raised the depression (Table 4). This result manifested that dietary SCC may contribute to regulating the assembly and secretion of lipoprotein in liver. MTP, a microsomal lumenal protein, is primarily responsible for transfer of TG and other lipids from their site of synthesis in the endoplasmic reticulum into the lumen during the assembly of VLDL [43-45]. VLDL produced by the liver are the major source of LDL in plasma. So the increase of MTP activity and expression accelerates the secretion of hepatic lipids in the form of lipoprotein. Evidence in this study displayed that OA supplementation significantly inhibited the MTP activity, which also explained the lipid accumulation in liver induced by dietary OA; While the SCC addition to the fatty liver rats elevated the MTP activity (Figure 5), which positively related to the increased serum lipid levels and the decreased hepatic TG concent in the SCC-feeding rats.Thus, this finding led to the suggestion that the enhancement of TG secretion from liver was another pathway of lipid-lowering mechanism of dietary SCC.

In Gao's study, the long chain base (LCB) of SCC exert as much effect as the cerebroside itself in lowering hepatic lipid levels in mice, which suggests that the LCB might take responsibility for the regulation of hepatic lipid levels [46]. This result provides elementary references for the relationship based on the structure and the activity of the cerebroside but it still deserves further investigation.

\section{Conclusions}

Supplementation with dietary SCC alleviated OAinduced fatty liver by attenuating TG synthesis through the down-regulation of fatty acid synthesis and improving TG secretion from liver. Findings of the present study also supported that SCC might be useful in the preservation of liver functions. But the relationship between the structure and the activity of the cerebroside still requires further investigation.

\section{Competing interests}

The authors declare that they have no competing interests.

\section{Authors' contributions}

BZ, CX and YW contributed in design, experimental work, analysis and publication of results. BZ and $Y W$ were responsible for drafting the manuscript. CX, XH and ZL participated in the design of the study, animal studies and performed statistical analysis. JX and JFW were in charge of the sample preparation and discussing the results. YX participated in the design of the study and statistical analysis. CX and TY participated in drafting the manuscript, discussion of results and providing funding for the study. All authors have read and approved this manuscript.

\section{Acknowledgements}

This work is supported by the National Natural Science Foundation of China (30972285) and International science \& technology cooperation program of China (2010DFA31330).

\section{Author details}

${ }^{1}$ College of Food Science and Engineering, Ocean University of China, Qingdao, China. ${ }^{2}$ Department of Applied Biological Sciences, Saga University, Saga, Japan.

Received: 29 December 2011 Accepted: 14 April 2012 Published: 8 May 2012

\section{References}

1. Farrell GC, Larter CZ: Nonalcoholic fatty liver disease: from steatosis to cirrhosis. Hepatology 2006, 43:99-112.

2. Farres J, Pujol A, Coma M, Ruiz JL, Naval J, Mas JM, Molins A, Fondevila J, Aloy P: Revealing the molecular relationship between type 2 diabetes and the matabolic changes induced by a very-low-carbohydrated lowfat ketogenic diet. Nutr Metab 2010, 7:88.

3. Pagano G, Pacini G, Musso G, Gambino R, Mecca F, Depetris N, Cassader M, David E, Cavallo-Perin P, Rizzetto M: Non-alcoholic steatohepatitis, insulin resistance and metabolic syndrome: further evidence for an etiologic association. Hepatology 2002, 35:367-372.

4. Nagao K, Inoue N, Wang YM, Shirouchi B, Yanagita T: Dietary conjugated linoleic acid alleviates nonalcoholic fatty liver disease in Zucker ( $\mathrm{fa} / \mathrm{fa}$ ) rats. J Nutr 2005, 135:9-13.

5. Angulo P, Lindor K: Non-alcoholic fatty liver disease. J Gastroenterol Hepatol 2002, 17:186-190.

6. Larson BL, Hegarty HM: Orotic acid in milks of various species and commercial dairy products. J Dairy Sci 1979, 62:1641-1644.

7. Cha JY, Mameda Y, Yamamoto K, Oogami K, Yanagita T: Association between hepatic triacylglycerol accumulation induced by administering orotic acid and enhanced phosphatidate phosphohydrolase activity in rats. Biosci Biotechnol Biochem 1999, 62:508-513. 
8. Wang YM, Hu XQ, Xue Y, Li ZJ, Yanagita $T$, Xue $\mathrm{CH}$ : Study on possible mechanism of orotic acid-induced fatty liver in rats. Nutrition 2010, in press.

9. Hamilton RL, Guo LSS, Felker T, Chao Y, Havel RJ: Nascent high density lipoprotein from liver perfusates of orotic acid fed rats. J Lipid Res 1986, 27:967-978.

10. Yanagita T, Oogami K, Yamamoto T, Cha JY, Nunez J: Triglyceride metabolism of fatty liver and the prevention by dietary $n-3$ fatty acid. Proc Jpn Conf Biochem Lipids 1995, 38:3-6.

11. Cha JY, Cho YS, Kim I, Anno T, Rahman SM, Yanagita T: Effect of hesperetin, a citrus flavonoid, on the liver triacylglycerol content and phosphatidate phosphohydrolase activity in orotic acid-fed rats. Plant Food Hum Nutr 2001, 56:349-358

12. Hu XQ, Wang YM, Wang JF, Xue Y, Li ZJ, Nagao K, Yanagita T, Xue CH: Dietary saponins of sea cucumber alleviate orotic acid-induced fatty liver in rats via PPARa and SREBP-1c signaling. Lipids Health Dis 2010, 9:25.

13. Buang Y, Wang YM, Cha JY, Nagao K, Yanagita T: Dietary phosphatidylcholine alleviates fatty liver induced by orotic acid. Nutr 2005, 21:867-873.

14. Suzuki H, Park WK, Lim SY: Analyses of glycolipids in clove, red pepper, and nutmeg by high-performance liquid chromatography. J Food Sci 2000, 65:931-933.

15. Tang J, Meng XJ, Liu H, Zhao JL, Zhou LG, Qiu MH, Zhang XM, Yu Z, Yang FY: Antimicrobial activity of sphingolipids isolated from the stems of cucumber (cucumis sativus I.). Molecules 2010, 15:9288-9297.

16. Chang YJ, Huang JR, Tsai YC, Hung JT, Wu D, Fujio M, Wong CH, Yu AL: Potent immune-modulating and anticancer effects of NKT cell stimulatory glycolipids. Proceedings of the National Academy of Sciences of the United States of America 2007, 104:10299-10304.

17. Nakagawa R, Nagafune I, Tazunoki $Y$, Ehara H, Tomura H, lijima R, Motoki K, Kamishohara M, Seki S: Mechanisms of the antimetastatic effect in the liver and of the hepatocyte injury induced by a-galactosylceramide in mice. J Immunol 2001, 166:6578-84.

18. Wu D, Fujio M, Wong CH: Glycolipids as immunostimulating agents. Bioorgan Med Chem 2008, 16:1073-1083.

19. Rumiana K, Martin C: Phases and phase transitions of the sphingolipids. BBA 1995, 1255:213-236

20. Mbosso EJ, Ngouela S, Nguedia JC, Penlap V, Rohmer M, Tsamo E: Spathoside, a cerebroside and other antibacterial constituents of the stem bark of Spathodea campanulata. Nat Prod Res 2008, 22:296-304.

21. Kim SY, Choi YH, Huh H, Kim J, Kim YC, Lee HS: New bioactive cerebroside from Lycium chinense fruits. J Nat Prod 1997, 60:274-6.

22. Hattori T, Kokura S, Okuda T, Okayama T, Takagi T, Handa O, Naito Y, Yoshida N, Yoshikawa T: Antitumor effect of whole body hyperthermia with alpha-galactosylceramide in a subcutaneous tumor model of colon cancer. Int J Hyperthermia 2007, 23:591-8.

23. Boggs JM, Gao W, Hirahara Y: Myelin glycosphingolipids, galactosylceramide and sulfatide, participate in carbohydratedcarbohydrate interactions between apposed membranes and may form glycosynapses between oligodendrocyte and/or myelin membranes. Biochem Biophys Acta 2008, 1780:445-455.

24. Jeffrey Cohn S, Wat Elaine, Kamili Alvin, Tandy Sally: Dietary phospholipids, hepatic lipid metabolism and cardiovascular disease. Current Opinion in Lipidology 2008, 19:257-262.

25. Tanaka K, Nishizono S, Kase A, Ogura S, Kurita M, Murakami T, Kugino K, Matsumoto $H$, Ikeda I: Effects of dietary black sea cucumber on serum and liver lipid concentrations in rats. Journal of Japanese Society of Nutrition and Food Science 2003, 56:175-9.

26. Wang JF, Pang L, Wang YM, Gao S, Xue CH: Studies on the Treatment effects of pearsonothuria graeffei and apostichopus japonicus on hyperlipidemia rats. Periodical of Ocean University of China 2007, 4:597-600.

27. Yamada K, Sasaki K, Harada Y, Isobe R, Higuchi R: Isolation and structure of glucocerebrosides from the sea cucumber Holothuria pervicax. Chem Pharm Bull 2002, 50:1467-1470.

28. Folch J, Lees M, Slane-stanley $\mathrm{GH}$ : A simple method for the isolation and purification of total lipids from animal tissues. J Biol Chem 1957, 226:497-506.

29. Barlett GR: Colorimetric assay methods for free and phosphorylated glyceric acids. J Biol Chem 1958, 234:466-469.

30. Ikeda I, Cha JY, Yanagita T, Nakatani N, Oogami K, Imaizumi K, Yazawa K. Effects of dietary alpha-linolenic, eicosapentaenoic and docosahexaenoic acids on hepatic lipogenesis and beta-oxidation in rats. Biosci Biotechnol Biochem 1998, 62:675-80.

31. Ochoa $S$, Mehler AH, Kornberg A: Biosynthesis of dicarboxylic acids by carbondioxide fixation. I. Isolation and properties of an enzyme from pigeon liver catalyzing the reversible oxidative decarboxylation of Lmalicacid. J Biol Chem 1948, 174:979-1000.

32. Glock GE, Mclean P: Glucose 6-phosphate dehydrogenase activity of rat liver. Nature 1952, 170:119-20.

33. Lowry OH, Rosebrough NJ, Farr AL, Randall RJ: Protein measurement with the Folin phenol reagent. J Biol Chem 1951, 193:265-75.

34. Valenti L, Fracanzani AL, Dongiovanni P, Santorelli G, Branchi A, Taioli E, Fiorelli G, Fargion S: Tumor necrosis factor alpha promoter polymorphisms and insulin resistance in nonalcoholic fatty liver disease. Gastroenterology 2002, 2:274-80.

35. Zigmond E, Zangen SW, Pappo O, Sklair-Levy M, Lalazar G, Zolotaryova L, Raz I, llan Y: B-Glycosphingolipids improve glucose intolerance and hepatic steatosis of the cohen diabetic rat. Am J Physiol Endocrinol Metab 2009, 296:72-78.

36. Horton JD, Goldstein JL, Brown MS: SREBPs: activators of the complete program of cholesterol and fatty acid synthesis in the liver. J Clin Invest 2002, 109:1125-31.

37. Osborne TF: Sterol regulatory element-binding proteins (SREBPs): key regulators of nutritional homeostasis and insulin action. J Biol Chem 2000, 275:32379-82.

38. Ahmed MH, Byrne CD: Modulation of sterol regulatory element binding proteins (SREBPs) as potential treatments for non-alcoholic fatty liver disease (NAFLD). Drug Discov Today 2007, 12:740-7.

39. Rutledge AC, Adeli K: Fructose and the metabolic syndrome: pathophysiology and molecular mechanisms. Nutr Rev 2007, 65:S13-23.

40. Reddy JK, Hashimoto T: Peroxisomal beta-oxidation and peroxisome proliferator activated receptor alpha: an adaptive metabolic system. Annu Rev Nutr 2001, 21:193-230.

41. Miyazawa S, Furuta S, Hashimoto T: Reduction of beta-oxidation capacity of rat liver mitochondria by feeding orotic acid. Biochim Biophys Acta 1982, 711:494-502.

42. Morifuji M, Aoyama Y: Dietary orotic acid affects antioxidant enzyme mRNA levels and oxidative damage to lipids and proteins in rat liver. J Nutr Biochem 2002, 13:403-410.

43. Hussain MM, lqbal J, Anwar K, Rava P, Dai K: Microsomal triglyceride transfer protein: a multifunctional protein. Front Biosci 2003, 8:500-506

44. Sundaram M, Yao Z: Recent progress in understanding protein and lipid factors affecting hepatic VLDL assembly and secretion. Nutr Metab 2010, 7:35.

45. Jun DW, Han JH, Jang EC, Kim SH, Kim SH, Jo YJ, Park YS, Chae JD: Polymorphisms of microsomal triglyceride transfer protein gene and phosphatidylethanolamine $\mathrm{N}$-methyltransferase gene in alcoholic and nonalcoholic fatty liver disease in Koreans. Eur J Gastroenterol Hepatol 2009, 6:667-72.

46. Gao Z, Zhou X, Hu XQ, Xue CH, Xu J, Wang YM: Effects of sea cucumber cerebroside and its long-chain base on lipid and glucose metabolism in obese mice. Zhejiang Da Xue Xue Bao Yi Xue Ban 2012, 41:60-64.

\section{doi:10.1186/1476-511X-11-48}

Cite this article as: Zhang et al:: Dietary sea cucumber cerebroside

alleviates orotic acid-induced excess hepatic adipopexis

in rats. Lipids in Health and Disease 2012 11:48. 